\title{
Urinary Calculi and the Consumption of Analgesics*
}

\author{
JOHN E. BLACKMAN, M.B., F.R.C.S., F.R.A.C.s. ; GEOFFREY R. GIBSON, M.B., F.R.C.S., F.R.A.C.s. \\ JOHN N. LAVAN, M.B.; HARRY M. LEAROYD, M.B., F.R.c.s., F.R.A.C.S. \\ SOLOMON POSEN, M.D., M.R.C.P., F.R.A.C.P.
}

Brit. med. F., 1967, 2, 800-802

There are many causes for stones in the urinary tract (Melick and Henneman, 1958 ; Boyce and Bradshaw, 1961; Maurice and Henneman, 1961). These include the presence of urinary solutes in abnormally high concentrations (Hodgkinson and Pyrah, 1958 ; Nordin and Robertson, 1966), a variety of factors diminishing their solubility (Elliot et al., 1961; Howard et al., 1962 ; Metcalfe-Gibson et al., 1965), and anatomical abnormalities favouring their precipitation (Boyce and King, 1963). In about half the patients no cause for stone formation is found (Melick and Henneman, 1958).

During a recent survey of 266 consecutive patients referred for the investigation of urinary calculi it was found that 43 of them gave a history of heavy consumption of analgesics (Lavan et al., 1966). A search of the literature showed that in spite of many papers on the nephrotoxicity or otherwise of these compoumds (Gilman, 1964; Dawborn et al., 1964 ; Rubenstein et al., 1964 ; Fordham et al., 1965 ; Lancet, 1966) there appears to have been no systematic investigation into the association between stones in the urinary tract and the regular consumption of analgesics. Such an association is reported in this paper.

\section{Patients and Methods}

For a diagnosis of urinary calculus to be made one or more of the following criteria had to be present. (1) A statement by the patient that he had passed "a stone" per urethram. This was accepted even if the material was not produced for inspection and analysis. (2) A statement by a medical practitioner that he had removed a stone from the patient. (3) Urography demonstrating radio-opaque material or a radiotranslucent filling defect in the urinary passages. (4) A history of ureteric colic consisting of at least three out of the following four features: (a) unilateral pain in the loin, groin, or intermediate sites ; $(b)$ intermittent pain in these areas ; $(c)$ pain lasting for 1 to 24 hours; and $(d)$ urinary symptoms such as haematuria, dysuria, or frequency occurring within 24 hours of the onset of pain.

In the entire series of 266 patients, 12 were diagnosed on the basis of colic alone while nine had radiotranslucent material in their urinary passages.

Approximately two-thirds of the patients came from three private urological practices (J.E.B., G.R. G., and H.M. L.), while the remainder were private or hospital patients referred to us for investigation. There were no factors in the selection of patients other than the diagnostic criteria outlined. Twelve patients referred for investigation were not included in the survey because they did not fulfil these criteria.

During the interview each patient was questioned about his consumption of milk, antacids, analgesics, purgatives, and sedatives (in that order). The answers were graded into three categories: " nil or occasional," " regular," and " heavy." In order to qualify for inclusion in the "heavy" group for any compound the patient had to admit that he took three or more * From the Department of Medicine, University of Sydney, and the
Department of Urology, Sydney Hospital. tablets, powders, or teaspoonfuls of liquid medication per day for more than one year (Lavan et al., 1966).

The patients were asked about the presence or otherwise of epigastric pain, its relief by antacids, and its investigation by means of a barium meal. If a barium-meal examination had been performed and the patient was subsequently told he had a peptic ulcer this diagnosis was accepted even when the radiologist could not be contacted for confirmation.

Other investigations carried out on these patients included in each case a serum calcium, a 24-hour urine calcium, a blood urea nitrogen, a urine $\mathrm{pH}$ after oral ammonium chloride, an intravenous pyelogram, and a microscopical examination and culture of a voided midstream specimen of urine. The urine was arbitrarily classified as "infected" if both the following conditions were fulfilled: (a) the sediment contained five or more white cells per high-power field, and $(b)$ there was any bacterial growth on culture.

The control group consisted of 268 male and 221 female general hospital patients who answered "no" to each of the two questions: "Have you ever passed a stone from the bladder?" and "Have you ever had a stone in the kidney ?" These subjects were matched with the stone patients for age groups but were otherwise unselected. They were questioned about their consumption of analgesics in the same manner as the stone patients and were similarly classified into three categories. Their answers have been reported as part of a previous communication (Lavan et al., 1966).

\section{Results}

Table I shows the results of our investigations regarding the consumption of analgesics. Of the 103 female patients with renal calculi 28 were classified as "heavy" consumers of analgesics against 29 out of 221 female patients in the control group. This difference is significant at the $1 \%$ level $\left(x^{2}=\right.$ 7.515). Among male stone-formers the consumption of analgesics was no more frequent than among the controls. None of the female patients in the "heavy" analgesic group was diagnosed on the basis of colic alone and none of these patients had radiotranslucent material in their urinary passages.

TABle I.-Consumption of Analgesics by 266 Patients with Renal Calculi and 489 Control Subjects

\begin{tabular}{|c|c|c|c|c|c|}
\hline & & & \multirow{2}{*}{$\begin{array}{l}\text { No. } \\
\text { Investi- } \\
\text { gated }\end{array}$} & \multicolumn{2}{|c|}{$\begin{array}{c}\text { " Heavy " Consumption } \\
\text { of Analgesics }\end{array}$} \\
\hline & & & & No. Admitting & No. Denying \\
\hline $\begin{array}{l}\text { Male stone-formers. } \\
\text { Male controls } \\
\text { Female stone-formers } \\
\text { Female controls } \quad \text {. }\end{array}$ & $\begin{array}{l}\cdots \\
\cdots \\
\cdots\end{array}$ & $\begin{array}{l}\cdots \\
\cdots \\
\cdots\end{array}$ & $\begin{array}{l}163 \\
268 \\
103 \\
221\end{array}$ & $\begin{array}{l}17(10.4 \%) \\
24(9.0 \%) \\
28(27.2 \%) \\
29(13.1 \%)\end{array}$ & $\begin{array}{r}146(89.6 \%) \\
2.44(91.0 \%) \\
75(72 \cdot 8 \%) \\
192(86.9 \%)\end{array}$ \\
\hline
\end{tabular}

Table II compares some of the features of the 28 female patients with renal calculi who admitted heavy consumption of analgesics with those of the 75 female stone-formers denying such consumption. It can be seen that the prevalence of urinary infection was greater in the group admitting to the consumption of analgesics, that there were more patients with a 
history of peptic ulcer in the " heavy analgesic" group, and that the prevalence of hypercalciuria (urine calcium in excess of $300 \mathrm{mg} . / 24 \mathrm{hr}$.) was greater in the group denying heavy consumption of analgesics. These differences, though suggestive, could be validated statistically only in relation to peptic ulcer. There was no difference between the mean blood urea nitrogen

TABLE II.-Results of Some Investigations in the Two Groups of Female Stone-formers

\begin{tabular}{|c|c|c|c|c|}
\hline & \multicolumn{2}{|c|}{$\begin{array}{c}\text { " Heavy " Consumption } \\
\text { of Analgesics }\end{array}$} & \multirow{2}{*}{$\chi^{2}$} & \multirow{2}{*}{ P Value } \\
\hline & $\begin{array}{l}\text { Patients } \\
\text { Admitting }\end{array}$ & $\begin{array}{l}\text { Patients } \\
\text { Denying }\end{array}$ & & \\
\hline $\begin{array}{l}\text { Prevalence of urinary in- } \\
\text { fection ... } \\
\text { Prevalence of radiologically } \\
\text { diagnosed peptic ulcer. } \\
\text { Prevalence of hypercalci- } \\
\text { uria } \\
\text { Family history of calculi.. }\end{array}$ & $\begin{aligned} 53.6 \% & (15 / 28) \\
21.4 \% & (6 / 28) \\
3.7 \% & (1 / 27) \\
14.3 \% & (4 / 28)\end{aligned}$ & $\begin{array}{c}32.9 \%(23 / 70) \\
5.3 \%(4 / 75) \\
17 \cdot 1 \%(12 / 70) \\
24.0 \%(18 / 75)\end{array}$ & $\begin{array}{l}2.796 \\
4.329 \\
1.984 \\
0.66\end{array}$ & $\begin{array}{l}<0.1>0.05 \\
<0.05>0.02 \\
>0.1 \\
>0.3\end{array}$ \\
\hline
\end{tabular}

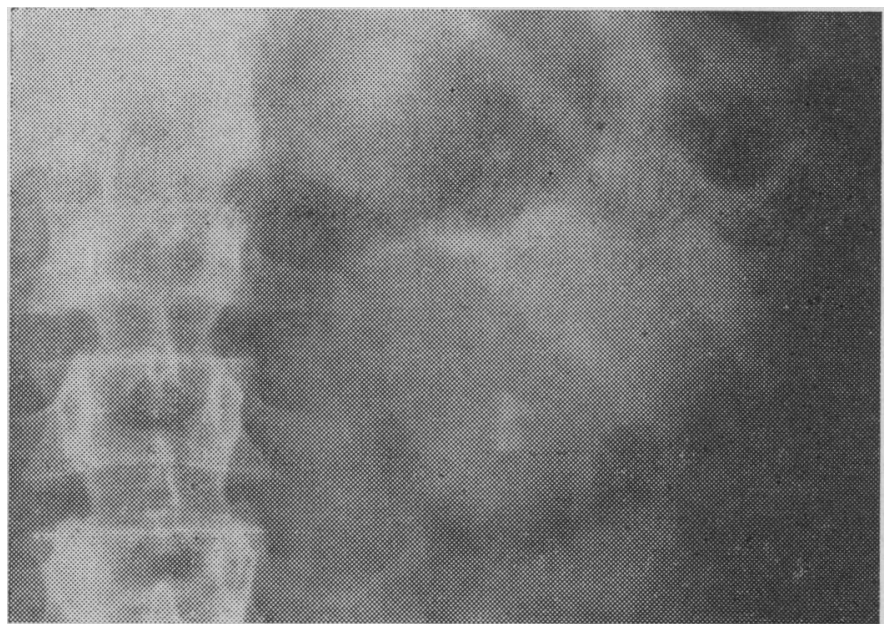

FIG. 1.-Plain $x$-ray film of the left kidney showing a triangular stone near the lower pole. The patient had been taking "about six" powders containing phenacetin, acetylsalicylic acid, and caffeine daily for "many" years.

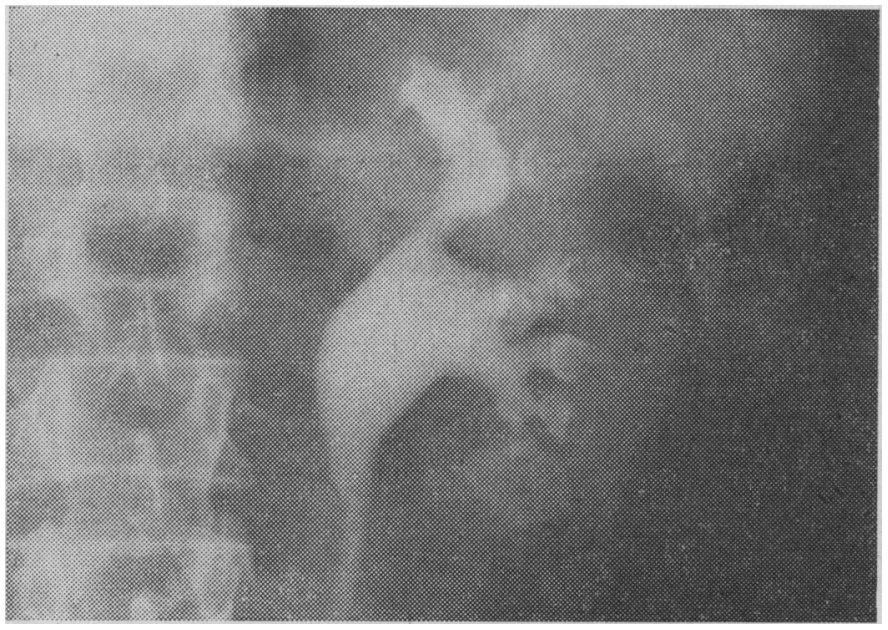

FIG. 2.-Intravenous pyelogram of the kidney shown in Fig. 1. The triangular stone is seen to be associated with a cavity from which the pyramid has disappeared.

of the two groups of patients, and a familyt history of renal calculi was obtained in approximately $20 \%$ of patients in both groups.

Information was available on the type of analgesic taken in 24 of the 28 female patients in the "heavy consumption" group. In all cases but two the analgesic was a mixture containing phenacetin, acetylsalicylic acid, and caffeine (Lavan et

† The family histery in this survey was restricted to parents, siblings, and children. al., 1966). Some patients as well as some of the control subjects habituated to these drugs took up to 24 analgesic powders -that is, $4 \mathrm{~g}$. of phenacetin, $4 \mathrm{~g}$. of acetylsalicylic acid, and $700 \mathrm{mg}$. of caffeine-daily.

In several patients admitting to heavy consumption of analgesics a classical radiological appearance could be recognized (Figs. 1-3). This consisted of loss of pyramidal tissue and the presence of a triangular stone. We have not seen this appearance in any patients other than those taking analgesics regularly.

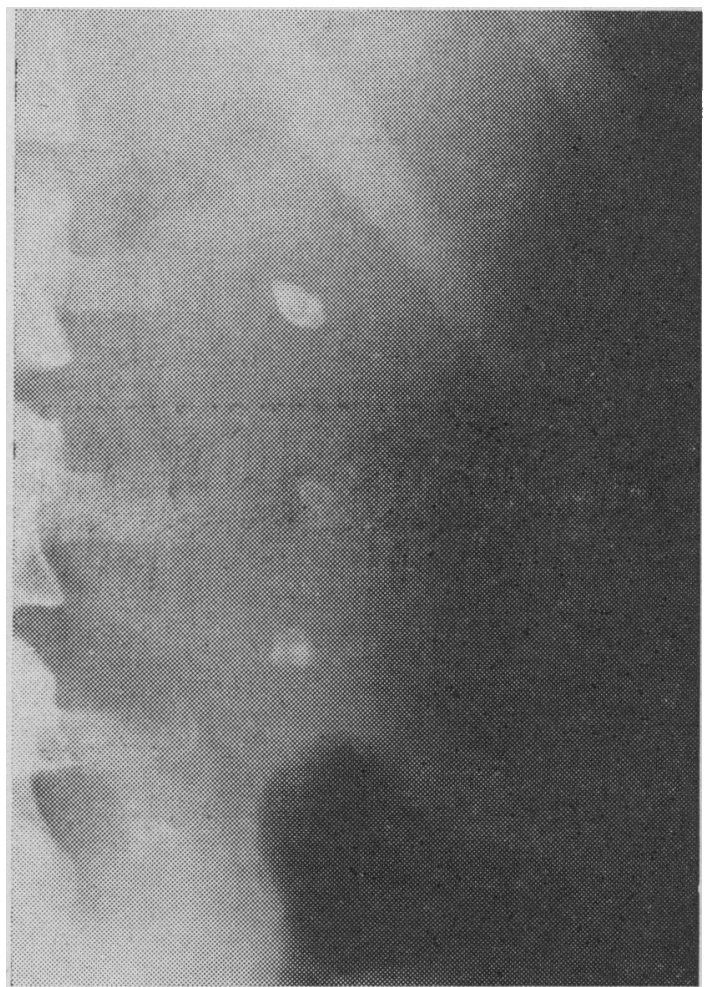

FIG. 3.-Typical appearance of papillary calcification with transradiant centres in a 45-year-old woman admitting to heavy analgesic consumption. Note the triangular opacity in the line of the ureter.

\section{Discussion}

While it is not possible from this study to ascribe a causeand-effect relation to analgesic consumption and stone formation, it scems very likely that at least some of the patients habituated to analgesics form calculi because of the calcification of necrotic papillary material. The association between analgesics and papillary necrosis has been repeatedly described (Larsen and Møller, 1959 ; Lindeneg et al., 1959 ; Jacobs and Morris, 1962 ; Burry et al., 1966), though the exact pathogenesis remains obscure (Dawborn et al., 1966).

With the increasing clinical recognition of this condition, it seems surprising that the entity of renal calculi following recovery from papillary necrosis has not been described more often. We were able to find only one previous account of this sequence of events (Hultengren, 1961).

A clearly recognizable syndrome emerged from this study. The patient was typically a woman aged 35-55 who had been consuming six to twelve analgesic powders a day for a number of years before the onset of any urinary symptoms. During this time she was found to have a peptic ulcer (Dawborn et al., 1966) or to have developed epigastric pain relieved by antaci, preparations. During the late 1950s and early 1960s she had one or more episodes of "severe pyelonephritis" necessitating admission to hospital. After antibiotic therapy there was. symptomatic improvement, followed within one to two years by the recognition of the presence of a urinary calculus. Wher this was available for analysis it was found to contain calcium, 
oxalate, phosphate, ammonium, magnesium, or carbonate-that is, the composition did not differ from that of stones found in a population denying the consumption of analgesics.

It may be argued that as we have accepted renal colic and radiotranslucent material in the urinary passages as criteria for urinary stone formation, a number of patients may have been included whose renal colic and radiological appearances were due to necrotic papillae (Lindholm, 1960). However, all female patients in the "heavy" analgesic group had radiological evidence of calcified material in the urinary tract. While papillary debris may have been initially responsible for the calcification, this does not seem to us a good reason for not calling this material a "stone."

\section{Summary}

Forty-five of a series of 266 patients with renal calculi gave a history of heavy consumption of analgesics. A mechanism is suggested for the association between the two conditions.

Prolonged consumption of analgesics with calcification of necrotic papillary material should be included among the causes of renal calculi.

Drs. F. C. Neale, F. Jennis, and J. T. Wright are hereby thanked for their help in the investigation of these patients.

This study was supported by the Postgraduate Medical Foundation, the University of Sydney, the N.S.W. State Cancer Council, and the Edanros Research Foundation Inc., New York.
REFERENCES

Boyce, W. H., and Bradshaw, H. H. (1961). F. Urol. (Baltimore), 85, 223. - and King, J. S. (1963). Ann. N.Y. Acad. Sci., 104, 563.

Burry, A. F., de Jersey, P., and Weedon, D. (1966). Med. F. Aust., 1, 873.

Dawborn, J. K., Fairley, K. F., Kincaid-Smith, P., and King, W. E. (1966). Quart. F. Med., 35, 69.

Kincaid-Smith, P., and McLaren, J. (1964). Aust. Ann. Med., 13, 217.

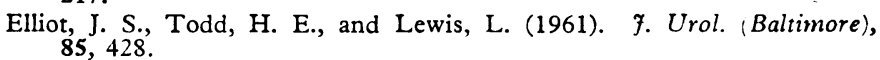

Fordham, C. C., Huffines, W. D., and Welt, L. G. (1965). Ann. intern. Med., 62, 738 .

Gilman, A. (1964). Amer. F. Med., 36, 167.

Hodgkinson, A., and Pyrah, L. N. (1958). Brit. F. Surg., 46, 10.

Howard, J. E., Thomas, W. C., Mukai, T., Johnston, R. A., and Pascoe, B. J. (1962). Trans. Ass. Amer. Phycns, 75, 301.

Hultengren, N. (1961). Acta chir. scand., Suppl. No. 277, p. 62.

Jacobs, L. A., and Morris, J. G. (1962). Med. F. Aust., 2, 531.

Lancet, 1966, 2, 1451.

Larsen, K., and Møller, C. E. (1959). Acta med. scand., 164. 53.

Lavan, J. N., Benson, W. J., Gatenby, A. H., and Posen, S. (1966). Med. F. Aust., 2, 694.

Lindeneg, O., Fischer, S., Pedersen, J., and Nissen, N. I. (1959). Acta med. scand., 165, 321 .

Lindholm. T. (1960). Ibid., 167, 319.

Maurice, P. F., and Henneman, P. H. (1961). Medicine (Baltimore), 40, 315.

Melick, R. A., and Henneman, P. H. (1958). New Engl. F. Med., 259, 307.

Metcalfe-Gibson, A., McCallum, F. M., Morrison, R. B. I., and Wrong, O. (1965). Clin. Sci., 28, 325.

Nordin, B. E. C., and Robertson, W. G. (1966). Brit. med. F., 1, 450.

Rubenstein, A. H., Abrahams, C., Stables, D. P., and Levin, N. W. (1964). Arch. intern. Med., 113, 378.

Brit. med. F., 1967, 2, 802-804

When Lyell (1956) first described toxic epidermal necrolysis few reports of cases showing any similarity to the disease had appeared. Subsequent series described only a few cases ; but, nevertheless, these reports indicate that the disease has a widespread distribution, that it is not uncommon, and that it is important to recognize it-since the average fatality rate has been at least $20 \%$.

Since Lyell's original description-which has not been bettered-little has been added to descriptions of the clinical or histological features of the condition. In particular I have found his subtitle of "An eruption resembling scalding of the skin" most apt, especially his emphasis on the absence of exudation and shock. Many observers have suggested a drug reaction in the aetiology of the condition, especially in adults, though infection has also been implicated by others (Beare, 1962). Holzel and Jacobs (1966) and Tyson et al. (1966) have suggested that haemolytic staphylococci may be concerned, and my own findings support this view.

\section{Patients Studied}

Between 1956 and 196731 children have been seen with the features of Lyell's toxic epidermal necrolysis (see Table). Some of the characteristics of the condition are discussed below.

\section{Clinical Course}

The disease starts as a localized lesion, followed by a sudden, widespread erythema and exfoliation of the skin with a period of critical illness lasting for some two to seven days. This is succeeded by a dramatic change in which the tenderness disappears, temperature subsides, and the patient is no longer ill. This moment is unmistakable and is highly reminiscent of the crisis previously associated with pneumonia.

All 31 cases occurred before the age of 10 ; of the 13 affected in the first year of life, seven were aged 4 weeks or under, the youngest patient developing the disease some 48 hours after birth. The disease was fatal in a 3-day-old child, though six other neonates made a complete recovey and some of the most severe cases were seen in the older children.

Of the total of 31 patients 18 were boys-while of the 13 patients under 1 year old nine were boys.

Complications were uncommon and included moderate respiratory infections (6 cases), dysuria (2 cases), delirium and muscle twitching ( 1 case). In this series there were no recurrences, and, though some of the earlier cases developed candida infection, it was found possible to eliminate them by appropriate nystatin cover.

\section{Drugs}

Only five children were found to have received drugs recently, before the onset of the condition. For example, one child (Case 1) was already suffering from juvenile dermatitis herpetiformis and had been treated with sulphamethoxypyridazine (Lederkyn) for over a year with good control of her rash. On admission, she was ill and $80 \%$ of her skin was affected by

* Consultant Dermatologist, Belfast City Hospital, Belfast 9. 